\title{
The physicochemical effect of sugar alcohol plasticisers on oxidised nanocellulose gels and extruded filaments
}

\author{
Marcus A. Johns $(\mathbb{D}) \cdot$ Rinat Nigmatullin - Emily D. Cranston $(\mathbb{D})$ Stephen J. Eichhorn $(\mathbb{D}$
}

Received: 22 September 2020/ Accepted: 7 June 2021/Published online: 8 July 2021

(C) The Author(s) 2021

\begin{abstract}
Oxidised nanocelluloses have previously shown promise for the production of extruded filaments with high tensile strength properties. However, they also exhibit poor wet strength due to swelling upon immersion in water. This has resulted in the use of chemical cross-linkers, or co-extrusion with multivalent cations, or cationic polymers, to inhibit this. Here, we report on the effect of incorporating sugar alcohols (glycerol, sorbitol and maltitol) in an oxidised nanocellulose gel before extrusion. Whilst their presence weakens the initial gel, they enable the
\end{abstract}

Supplementary information The online version contains supplementary material available at https://doi.org/10.1007/ s10570-021-03991-8.

M. A. Johns · E. D. Cranston

Department of Wood Science, The University of British Columbia, 2424 Main Mall, Vancouver,

BC V6T 1Z4, Canada

e-mail: marcus.a.johns@ubc.ca

E. D. Cranston

e-mail: emily.cranston@ubc.ca

R. Nigmatullin · S. J. Eichhorn $(\bowtie)$

Bristol Composites Institute, School of Civil, Aerospace, and Mechanical Engineering, University Walk, University of Bristol, Bristol BS8 1TR, UK

e-mail: s.j.eichhorn@bristol.ac.uk

E. D. Cranston

Department of Chemical and Biological Engineering, The University of British Columbia, 2360 East Mall,

Vancouver, BC V6T 1Z3, Canada continuous wet spinning of filaments that are stable in aqueous media without the need for post extrusion processing. We conclude that the relative hydrophilicity of the sugar alcohol and its ability to protonate surface carboxyl groups upon drying are key parameters regarding the physicochemical effects observed.

Keywords Oxidised nanocellulose $\cdot$ Sugar alcohols $\cdot$ Rheology $\cdot$ Tensile properties

\section{Introduction}

Cellulose nanofibrils (CNFs) are ideally suited for the development of advanced functional materials due to their biodegradability, biocompatibility, and excellent tensile properties (Moon et al. 2011; Wang et al. 2019b). They are primarily produced via mechanical fibrillation with additional chemical modificationsuch as (2,2,6,6-tetramethylpiperidin-1-yl)oxyl oroxidanyl (TEMPO) oxidation-used to ensure that the nanofibrils remain well dispersed in aqueous solutions under neutral conditions (De France et al. 2017). These oxidised cellulose nanofibrils (OCNFs) have been investigated for use in a variety of structures including gels, films, 3D scaffolds and spun filaments (De France et al. 2017; Alves et al. 2019; Wang et al. 2019b). Iwamoto et al. (2011) first reported the 
spinning of pure OCNF filaments, achieving a reported Young's modulus of $24 \mathrm{GPa}$ and ultimate tensile strength of $321 \mathrm{MPa}$ via shear-induced fibre alignment. Similar properties have been reported by Walther et al. (2011), Torres-Rendon et al. (2014), and Lundahl et al. (2016). However, the OCNF anionic surface groups make these fibres susceptible to humidity, with a significant loss in tensile strength (wet material strength $<1 \%$ that of the dry material) upon immersion in water (Lundahl et al. 2016). This is due to electrostatic repulsion of the fibres arising from deprotonation of the surface groups, resulting in expansion of the fibre and, ultimately, dispersion of fibrils when immersed in water (Johns et al. 2020).

To mitigate this, both coating and cross-linking of the filaments have been investigated. Lundahl et al. (2018) coated fibres in cellulose acetate and guar gum via coaxial wet spinning, retaining up to $10 \%$ of the dry tensile strength after immersion and reducing water absorption by up to $55 \%$. Vuoriluoto et al. (2017) retained approx. $80 \%$ of the filament dry tensile strength after immersion in water via benzophenone conjugation whilst Mittal et al. (2018) used 1,2,3,4butanetetracarboxylic acid to cross-link fibrils.

Chitosan has also been used as a counter-ion copolymer to generate filaments via interfacial polyelectrolyte complexation spinning (Grande et al. 2017; Toivonen et al. 2017). Complexes formed between the anionic carboxyl groups of OCNF and the cationic amine groups of chitosan inhibit repulsion between like charged groups, stabilising the resultant structure. This is also observed upon complexation with multivalent ions in both films (Benselfelt et al. 2019) and fibres (Mittal et al. 2019; Wang et al. 2019a). Interestingly, Wang et al. (2019a) also reported that extrusion into an acidic bath promoted hornification, due to protonation of the carboxyl groups, decreasing the filament moisture absorption by approximately $40 \%$ compared to fibres extruded into acetone, or methanol.

Alcohols have also been shown to decrease the repulsive interactions between OCNFs at low alcohol:water ratios, resulting in attraction between the fibrils in primarily aqueous solutions, as determined by small-angle $\mathrm{x}$-ray scattering (SAXS) (da Silva et al. 2018). We theorize that this interaction between an alcohol and the OCNFs could limit filament expansion upon immersion in water. Sugar alcohols (SAs), e.g. glycerol and sorbitol, are less volatile compared to other alcohols and a number are internationally approved for use in food products (Grembecka 2019). They are commonly used as natural-based plasticisers with hydrophilic biopolymers-including starch (Galdeano et al. 2009, Mathew, Dufresne 2002, Müller et al. 2008, Saberi et al. 2017, Talja et al. 2007), alginate (Jost et al. 2014; Tong et al. 2013), and chitosan (Suyatma et al. 2005)—making them ideal for use in this study given their potential applicability to produce biodegradable, and edible, films and filaments (Vieira et al. 2011). Most recently, SAs have been incorporated into chiral nematic cellulose nanocrystal structures to produce stable, flexible films that change colour in response to humidity (He et al. 2018; Meng et al. 2020; Xu et al. 2018).

Here, we report on the interaction between three SAs (glycerol, sorbitol, maltitol) and oxidised nanocellulose in the aqueous environment. The subsequent effect on the physicochemical properties of filaments produced from these systems and their response to immersion in water were also investigated.

\section{Materials}

Oxidised cellulose nanofibrils (OCNFs) (4 wt.\% aqueous suspension, sodium form, degree of modification: $25 \%$, calculated carboxyl group content: $0.711 \pm 0.011 \mathrm{mmol} \mathrm{g}^{-1}$ ) were provided by an industrial source. Acetone, glycerol and poly (allylamine hydrochloride) (PAH, MW: 120-200 $\mathrm{kg} \mathrm{mol}^{-1}$ ), were purchased from Sigma Aldrich (Gillingham, UK). Sorbitol was purchased from VWR International Ltd (Leicestershire, UK). Maltitol (97\%) was purchased from Thermo Fisher Scientific (Loughborough, UK). DI water (18.2 M $\Omega$ $\mathrm{cm}$ ) was produced using a Direct-Q 3 UV water purification system (Merck, Darmstadt, Germany).

\section{Experimental methods}

Gel production

The OCNF gel was diluted down to approx. $1.6 \mathrm{wt} . \%$ using DI water before being passed through an APV2000 laboratory homogenizer (SPX FLOW, Sussex, UK) seven times (pressures of 700, 1030, 1220, 1540, 1490, 1540 and $1530 \mathrm{MPa}$ respectively). The 
suspension was cooled on ice between each pass. The suspension was then placed in dialysis membrane and concentrated to $2.5 \mathrm{wt}$. $\%$ at ambient temperature in a fume hood. Atomic force microscopy analysis of the particles (Figures S1 and S2, Supplementary Information) revealed that the homogenization procedure degraded the majority (approx. 90\%) of the nanofibrils resulting in two distinct nanoparticle lengths (lower average: $159 \pm 4 \mathrm{~nm}$, upper average: $527 \pm 22 \mathrm{~nm}$ ) despite there being no difference in the particle height (average: $2.6 \pm 0.0 \mathrm{~nm}$ ). Samples (see Table S1, Supplementary Information for sample names) were generated via the addition of sugar alcohols (glycerol, sorbitol, maltitol), which were then left on a roller table overnight. Finally, these underwent an ultrasonication procedure using a digital sonifier 450 (Branson Ultrasonics Corporation, Connecticut, USA) for $2 \mathrm{~min}$ (10\% power, $30 \mathrm{~s}$ power followed by $30 \mathrm{~s}$ rest on ice) prior to use.

\section{Atomic force microscopy (AFM)}

Silicon wafers were treated with UV and ozone (UV/ Ozone ProCleaner ${ }^{\mathrm{TM}}$, BioForce Nanosciences Inc., Ames, IA, USA) for 15 min before being spin coated with a 0.1 wt.\% PAH solution using a WS-650-23 Spin Coater (speed: $3000 \mathrm{rpm}$; acceleration: $2300 \mathrm{rpm} \mathrm{s}^{-1}$; hold time: $30 \mathrm{~s}$; Laurell Technologies, North Wales, PA, USA), and rinsed with purified water. A 0.02 wt.\% OCNF suspension was spin coated onto the PAH-coated $\mathrm{Si}$ wafer for the individual particle analysis. All atomic force microscopy images were generated using a Jupiter XR atomic force microscope (Oxford Instruments, Oxfordshire, UK) in blue drive air tapping mode using an AC160TS-R3 lever (resonance frequency: $300 \mathrm{kHz}$; spring constant: $26 \mathrm{~N} \mathrm{~m}^{-1}$; tip material: Si; Asylum Research-Oxford Instruments, Santa Barbara, CA, USA). Images were post treated in Gwyddion (polynomial background substitution and alignment of rows) and the heights of individual particles determined. Particle length analysis was performed using ImageJ, all particles with circularity greater than 0.5 were automatically discarded.

\section{Rheometry}

All rheological tests on gel samples were performed with a TA Discovery Hybrid HR-1 rheometer (TA
Instruments, New Castle, USA). A cone (angle: $4^{\circ}$, diameter: $40 \mathrm{~mm}$ ) geometry was selected. Testing was carried out at a constant temperature of $25^{\circ} \mathrm{C}$. Angular frequency sweeps were performed between 0.4 and $100 \mathrm{rad} \mathrm{s}^{-1}$ at a constant strain of $1.5 \%$. Flow sweeps were performed between 0.001 and $100 \mathrm{~s}^{-1}$.

\section{Dynamic light scattering (DLS)}

Size measurements were performed on a Malvern Panalytical Zetasizer Nano-ZS (Malvern, United Kingdom). The 2.5 wt.\% OCNF suspension was diluted to 0.025 wt.\% using 2.9 wt.\% solutions of the SAs and apparent particle sizes were calculated from hydrodynamic radii using Stokes-Einstein equation and the assumption of spherical particles. For each sample, ten measurements were performed in triplicate. The number average of each particle distribution was calculated. The error presented is the standard error of three samples.

\section{Zeta-potential}

Zeta-potential measurements were performed on a Malvern Panalytical Zetasizer Nano-ZS (Malvern, United Kingdom). Two different sample preparation methods were used. Firstly, the SA modified gels were diluted to 0.025 wt.\% with $\mathrm{DI} \mathrm{H}_{2} \mathrm{O}$. Secondly, the OCNF suspension was diluted to 0.025 wt. \% using 2.9 wt.\% SA solutions. The electrophoretic mobilities were then converted to $\zeta$-potentials following Smoluchowski theory despite the assumptions inherent to this method. The error presented is the standard error of three samples.

\section{Quartz crystal microbalance (QCM)}

Silicon dioxide coated QCM sensors (Biolin Scientific, Gothenburg, Sweden) were first cleaned with nitrogen and then submitted to UV and ozone (UV/ Ozone ProCleaner ${ }^{\mathrm{TM}}$, BioForce Nanosciences Inc., Ames, IA, USA) for $15 \mathrm{~min}$. For the SA-OCNF interaction experiments, $200 \mu \mathrm{L}$ of the 2.5 wt. $\%$ OCNF suspension was spin coated onto the sensors using a WS-650-23 Spin Coater (speed: 3000 rpm; acceleration: $2300 \mathrm{rpm} \mathrm{s}^{-1}$; hold time: $30 \mathrm{~s}$; Laurell Technologies, North Wales, PA, USA). The spin coated films were annealed overnight in the oven at $70{ }^{\circ} \mathrm{C}$. The sensors were placed in a flow cell (QSense 
Analyzer, Biolin Scientific, Gothenburg, Sweden) and equilibrated in DI $\mathrm{H}_{2} \mathrm{O}$ overnight (flow rate: $0.005 \mathrm{~mL} \mathrm{~min}^{-1}$ ) at $\mathrm{RT}$, in order to obtain a stable baseline. For the experiment a $\mathrm{H}_{2} \mathrm{O} / 2.9$ wt.\% SA solvent exchange (flow rate: $0.1 \mathrm{~mL} \mathrm{~min}^{-1}$ ) was carried out to determine whether interaction was observed between the OCNF and SAs. An additional 2.9 wt.\% SA/ $\mathrm{D}_{2} \mathrm{O}$ exchange (flow rate: $0.1 \mathrm{~mL} \mathrm{~min}^{-1}$ ) was performed to determine the degree of SA interaction relative to the amount of water adsorbed on the OCNF surface. Briefly, a DI $\mathrm{H}_{2} \mathrm{O}$ baseline was recorded for $35 \mathrm{~min}$, after which the solvent was exchanged for 2.9 wt.\% SA aqueous solution and a change in resonance frequency $(\Delta f)$ was recorded for an additional $45 \mathrm{~min}$. The solvent was exchanged back to $\mathrm{DI} \mathrm{H}_{2} \mathrm{O}$ for 30 min, re-exchanged for the SA solution for $40 \mathrm{~min}$ and finally switched to $\mathrm{D}_{2} \mathrm{O}$ for $55 \mathrm{~min}$. The mass of bound analyte $\left(\Gamma_{\mathrm{i}}\right)$ was calculated using the complex Sauerbrey function in the QSense Dfind software (Biolin Scientific, Gothenburg, Sweden), which automatically considers all measurement harmonics, rather than just the singular harmonic used in the Sauerbrey equation (Eq. 1):

$\Gamma_{i}=-A \cdot C(\Delta f / m)_{f i l m, i}$

where $A$ is the area of sensor $\left(0.7854 \mathrm{~cm}^{2}\right)$; the $C$ is the sensitivity constant of the sensor $\left(0.177 \mathrm{mg} \mathrm{m}^{-2}\right.$ $\left.\mathrm{Hz}^{-1}\right), m$ is the measurement harmonic $(m=1,3,5$, $7 \ldots), i$ is the analyte $\left(\mathrm{H}_{2} \mathrm{O}, \mathrm{D}_{2} \mathrm{O}\right.$, SA solution), and $\Delta f_{\text {film }, i}$ is the measured change in resonant frequency of the OCNF film due to the analyte exchange (Eq. 2):

$$
\Delta f_{\text {film }, i}=\left([\Delta f / n]_{\text {film }}-[\Delta f / n]_{\text {baresubstrate }} /\left[\rho_{i} / \rho_{(i-1)}\right]-1\right)
$$

where $\Delta f_{\text {bare sensor }}$ is the measured change in the resonant frequency of a pristine $\mathrm{SiO}_{2}$ coated QCM sensor $(-54 \mathrm{~Hz})$ due to the solvent exchange; $\rho_{i}$ is the density of analyte $\left(\mathrm{H}_{2} \mathrm{O}: 1.104 \mathrm{~g} \mathrm{~cm}^{-3}\right.$ at $23{ }^{\circ} \mathrm{C} ; \mathrm{D}_{2} \mathrm{O}$ : $1.227 \mathrm{~g} \mathrm{~cm}^{-3}$ at $23{ }^{\circ} \mathrm{C}$; 2.9 wt.\% glycerol: $1.011 \mathrm{~g}$ $\mathrm{cm}^{-3}$ at $23{ }^{\circ} \mathrm{C} ; 2.9$ wt. $\%$ sorbitol: $1.014 \mathrm{~g} \mathrm{~cm}^{-3}$ at $23{ }^{\circ} \mathrm{C}$; 2.9 wt. $\%$ maltitol: $1.015 \mathrm{~g} \mathrm{~cm}^{-3}$ at $23{ }^{\circ} \mathrm{C}$ ) and $\rho_{(i-1)}$ is the density of the prior analyte. As the SAOCNF interaction was fully reversible, $\Gamma_{H 2 O}$ was normalized to the mass of $\mathrm{D}_{2} \mathrm{O}$ adsorbed. The densities of the $2.9 \mathrm{wt} . \%$ SA solutions were determined using a hydrometer.
For the $\mathrm{D}_{2} \mathrm{O}-\mathrm{SA} / \mathrm{OCNF}$ interaction experiments, $200 \mu \mathrm{L}$ of the SA modified 2.5 wt.\% OCNF suspensions (SA conc.: 0.7, 1.6, and $3.6 \mathrm{wt} . \%$ ) were spin coated and annealed. A DI $\mathrm{H}_{2} \mathrm{O} / \mathrm{D}_{2} \mathrm{O}$ exchange was

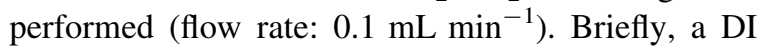
$\mathrm{H}_{2} \mathrm{O}$ baseline was recorded for $30 \mathrm{~min}$, the analyte was exchanged to $\mathrm{D}_{2} \mathrm{O}$ for $135 \mathrm{~min}$, and finally reexchanged to $\mathrm{DI} \mathrm{H}_{2} \mathrm{O}$ for $85 \mathrm{~min}$. Analysis proceeded as reported for the SA solution analyte experiments.

\section{Filament extrusion}

Gels were extruded into an acetone bath using a pump 11 elite syringe pump (Harvard Apparatus, Holliston,

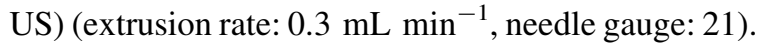
This was collected onto a glass cylinder before being allowed to dry at room temperature to generate a filament consisting of entangled OCNFs and the sugar alcohol. Acetone was chosen for the solvent bath due its miscibility with water; poor suitability for the dispersion of anionic nanocelluloses, and poor suitability as a solvent for sugar alcohols (Zhi et al. 2013).

\section{Scanning electron microscopy (SEM)}

SEM images were acquired using a TM3030Plus scanning electron microscope (Hitachi, Tokyo, Japan) (uncoated; secondary electron and backscatter combined image; acceleration voltage: $5 \mathrm{kV}$ ).

Fourier transform infrared spectroscopy (FTIR)

FTIR spectra were obtained using a Spectrum100 spectrometer (PerkinElmer, Waltham, USA) operating in ATR mode (range: $4000-600 \mathrm{~cm}^{-1}$; resolution: $1 \mathrm{~cm}^{-1}$; accumulation: 10 scans).

Thermogravimetric analysis (TGA)

Thermogravimetric analysis up to $600{ }^{\circ} \mathrm{C}$ was performed using a Q500 (TA Instruments, New Castle, DE) under nitrogen atmosphere. Briefly, the sample ( $\sim 10 \mathrm{mg}$ ) was held at $30{ }^{\circ} \mathrm{C}$ for $10 \mathrm{~min}$ before ramping to $600{ }^{\circ} \mathrm{C}$ at $10{ }^{\circ} \mathrm{C} \mathrm{min}{ }^{-1}$, held for $10 \mathrm{~min}$ and allowed to cool. 
Tensile testing

Single filaments were mounted between two plastic tabs, located on a 20-slot linear plastic cassette (gauge length: $30 \mathrm{~mm}$ ). Each filament was fixed onto the tabs using 3193 UV adhesive (DYMAX, Wiesbaden, Germany). Filament diameters were determined using an FDAS770 fibre dimensional analysis system (Diastron, Andover, UK). The diameter was measured at five different locations along the filament for each sample. Tensile testing was performed using an LEX820 high resolution extensometer (Dia-stron, Andover, UK) (load cell capacity: $20 \mathrm{~N}$; extension rate: $20 \mu \mathrm{m} \mathrm{s}^{-1}$ ) after determination of the filament diameter. Samples were tested to failure. Measurements were repeated for five lengths of each sample filament generated $(\mathrm{N}=1, \mathrm{n}=5)$.

Multi-channel confocal laser scanning spectroscopy (MCLSS)

For the expansion experiments, each sample was held in place using carbon tape. Water $(500 \mu \mathrm{L})$ was added after $7 \mathrm{~s}$. Spectral images were acquired using a Zeiss LSM 880 confocal microscope (405 nm diode laser, $5.0 \%$ power, Plan-Apochromat $10 \times / 0.45$ M27 objective, MBS-405 filter, 32 channels: $\lambda=411-695 \mathrm{~nm})$. The experiment was conducted for $30 \mathrm{~min}$, with a spectral image acquired every $0.52 \mathrm{~s}$. Spectral analysis was performed using the unmixing tool in ZEN 2.6 (blue edition) (Carl Zeiss AG, Oberkochen, Germany). Each image was sectioned into fifths and spectra for each section obtained, which were then averaged. The fibre diameter was estimated using Fiji imaging software. Briefly, images were converted to 8-bit before automatic thresholding. An ellipse was fitted to the threshold area and the minor axis determined.

\section{Statistical analysis}

Statistical analysis was performed using IBM SPSS Statistics software. A one-way analysis of variance (ANOVA) test was used to determine the statistical differences between the means of three or more samples, assuming equal variance, with Tukey posthoc comparison. Differences were considered significant with a confidence level of $0.95 \quad(95 \%$ confidence).

\section{Results and discussion}

Sugar alcohol interaction and resultant gel properties

The addition of SAs to the OCNF gel resulted in a decrease in both the storage (G') and loss (G") moduli compared to the unmodified gel (Fig. 1a). This indicates that SAs weaken the oxidised nanocellulose gel structure. The effect was most apparent for glycerol $\left(\tan (\delta)=0.60\right.$ at $4 \mathrm{rad} \mathrm{s}^{-1}$ compared to 0.33 for the unmodified gel), whilst the addition of sorbitol, or maltitol, had less of an effect $(\tan (\delta)=$ 0.51 and 0.47 at $4 \mathrm{rad} \mathrm{s}^{-1}$ respectively). This effect on gel structure was anticipated based on the paper by da Silva et al. (2018), who reported an increase in $\tan (\delta)$ in OCNF suspensions containing less than 20 wt.\% alcohol. Whilst the exact mechanism behind this is not yet fully understood, the relative hydrophobicity of the alcohol may play a role, with more hydrophilic alcohols producing stronger gels (da Silva et al. 2018). This observation is reflected here; the predicted $\mathrm{X} \log \mathrm{P} 3$ values, relative to the molecule hydrophobicity, are $-1.8,-3.1$, and -5.2 for glycerol, sorbitol, and maltitol respectively (PubChem 2020a, 2020b, 2020c), i.e. maltitol-the most hydrophilic SA-results in the strongest gels.

Whilst the presence of the SAs reduced the gel viscosity at low shear rates (Fig. 1b), no change was observed in the shear thinning yield point (circa. $2.5 \mathrm{~s}^{-1}$ ). The Ostwald-de Waele power law (Eq. 3) was fitted to the shear thinning regions:

$\mu=K \dot{\gamma}^{n-1}$

where $\mu$ is the viscosity ( $\mathrm{Pa} \mathrm{s}) ; K$ is the flow consistency index $(\mathrm{Pa} \mathrm{s}) ; \mathcal{L}$ is the shear rate $\left(\mathrm{s}^{-1}\right)$ and $n$ is the flow behaviour index (dimensionless). $n$ decreased for all SA types and contents to an average of 0.09 compared to 0.13 for the unmodified gel (Table S1, Table S2). This indicated that the SAcontaining gels were more susceptible to shear thinning, which could be explained by a weaker interaction between the fibrils, potentially due to the disruption of charge-charge interactions either by a reduction in the absolute surface charge, or by an increase in the interfibrillar distance. The SA weakening effect on the OCNF gel was also evident from the comparison of shear viscosity and complex 
(a)

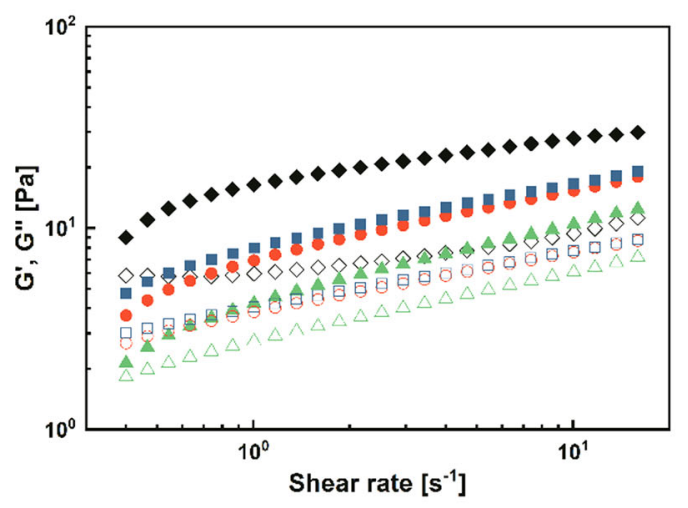

(c)

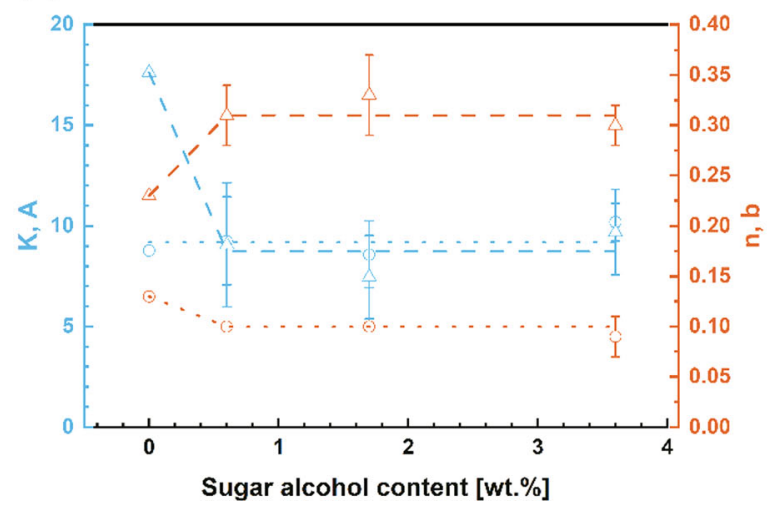

Fig. 1 Rheology of OCNF-SA gels. a Storage (G', closed symbols) and loss (G", open symbols) moduli. b Comparison between steady shear viscosity (closed symbols, left and bottom axes) and complex viscosity (open symbols, right and top axes). Temperature $25^{\circ} \mathrm{C}$. 2.5X100:0 (black diamonds); 2.5G60:40 (green triangles); 2.5S60:40 (red circles); and 2.5M60:40 (blue squares). c Average values for Eqs. 1 and 2 constants dependent

viscosity, obtained from steady shear and oscillatory rheology respectively (Fig. 1b). According to the CoxMerz rule, the viscosities of ideal polymer dispersions are equal at the same value of shear rate and angular frequency. Deviations from the Cox-Merz rule are usually induced by material structuring, which is impervious to the small deformations induced by oscillatory deformation but is distorted under the directional large deformations induced by steady shear. Large differences between the steady shear and complex viscosities were observed for the unmodified OCNF gel indicating strong network formation. However, smaller differences between the two viscosities were observed for SA-modified OCNF gels. The glycerol-modified gels almost obeyed the

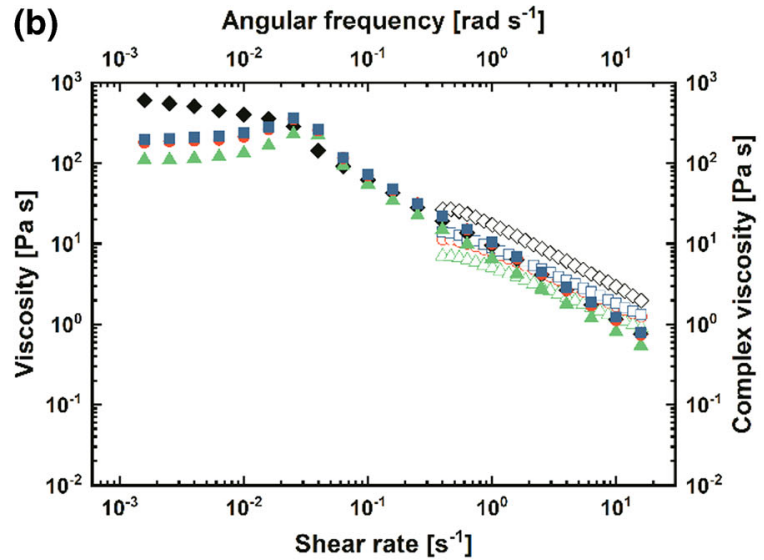

(d)

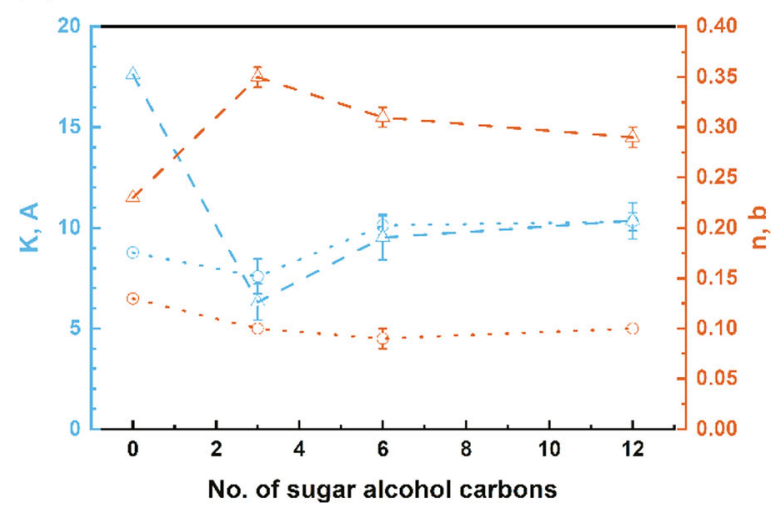

on SA content. d Average values for Eqs. 1 and 2 constants dependent on SA type. Viscosity constants $K$ (light blue open circles, dotted line) and $n$ (light brown open circles, dotted line); complex viscosity constants $A$ (light blue open triangles, dashed line) and $b$ (light brown open triangles, dotted line). $\mathrm{N}=3$, $\mathrm{n}=1$. Error: \pm S.E

Cox-Merz rule, indicating the weakest gel network compared with the unmodified OCNF gel and gels with the addition of maltitol and sorbitol.

Fitting the power law (Eq. 4) to the complex viscosity data determined a significant decrease in the parameter $A$ for the SA-modified gels (Table S1, Table S2), reflecting the increase in $\tan (\delta)$

$\eta^{*}=A(\omega)^{b-1}$

where $\eta^{*}$ is the complex viscosity (Pa s); $\omega$ is the angular frequency $\left(\mathrm{rad} \mathrm{s}^{-1}\right.$ ) and $A$ and $b$ are constants. However, minimal difference was observed in the $\zeta$ potential of the fibrils, averaging $-35.3 \mathrm{mV}$ across all samples, in the presence of the SAs (Table 1, Table S3). This meant that the presence of the SAs 
Table 1 Select properties of unmodified and SA-modified OCNF gels. SA type is the average of the three different concentrations for each SA; SA content is the average of the three different SAs for each concentration. $N=9, n=1$. Error: \pm S.E

\begin{tabular}{|c|c|c|c|c|c|}
\hline \multicolumn{2}{|l|}{ Sample } & \multirow{2}{*}{ 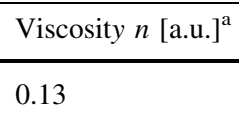 } & \multirow{2}{*}{$\frac{\text { Complex viscosity } A[\mathrm{~Pa} \mathrm{~s}]^{\mathrm{b}}}{17.6}$} & \multirow{2}{*}{$\frac{\zeta \text {-potential }[\mathrm{mV}]^{\mathrm{c}}}{-35.6}$} & \multirow{2}{*}{$\frac{{\text { Gaussian area }[\%]^{\mathrm{d}}}^{0.4}}{0.4}$} \\
\hline $2.5 \times 100: 0$ & & & & & \\
\hline \multirow[t]{3}{*}{ SA Type } & Glycerol & $0.10 \pm 0.00$ & $6.3 \pm 0.9$ & $-34.4 \pm 0.2$ & $1.1 \pm 0.2$ \\
\hline & Sorbitol & $0.09 \pm 0.01$ & $9.5 \pm 1.1$ & $-34.7 \pm 0.5$ & $0.8 \pm 0.1$ \\
\hline & Maltitol & $0.10 \pm 0.00$ & $10.4 \pm 0.9$ & $-35.7 \pm 0.1$ & $0.7 \pm 0.1$ \\
\hline \multirow[t]{3}{*}{ SA Content } & 0.6 wt. $\%_{\text {gel }}$ & $0.10 \pm 0.00$ & $9.1 \pm 3.1$ & $-35.4 \pm 0.4$ & $0.9 \pm 0.0$ \\
\hline & 1.7 wt. $\%_{\text {gel }}$ & $0.10 \pm 0.00$ & $7.5 \pm 2.1$ & $-34.8 \pm 0.6$ & $1.0 \pm 0.2$ \\
\hline & 3.6 wt. $\%_{\text {gel }}$ & $0.09 \pm 0.02$ & $9.7 \pm 2.1$ & $-34.7 \pm 0.4$ & $0.8 \pm 0.2$ \\
\hline
\end{tabular}

${ }^{\mathrm{a}}$ Viscosity flow behaviour index $(n)$ determined from steady-shear rheology; ${ }^{\mathrm{b}}$ Scaling factor $(A)$ determined from oscillatory rheology; ${ }^{c} \zeta$-potential determined from gels diluted to $0.02 \mathrm{wt} . \%$ OCNF; ${ }^{\mathrm{d}}$ Area of fitted Gaussian curve centred at $0.13-0.14 \AA^{-1}$ determined from SAXS Kratky plot

did not reduce the surface charge of the fibrils - which would result in particle aggregation and syneresis, such as occurs upon acidification of the suspension (Alves et al. 2020; Johns et al. 2020)_but rather disrupted the interfibrillar repulsive interactions that are responsible for the gel behaviour of OCNFs (Crawford et al. 2012; Schmitt et al. 2018). Importantly, increasing the SA content of the gels did not significantly affect the calculated parameters for either the viscosity and complex viscosity (Fig. 1c), whilst the choice of SA, denoted by the number of carbons present, did (Fig. 1d). This suggested that only SA molecules adsorbed onto the OCNF surfaces affected the rheological properties; excess SA in the suspension had no impact.

Further evidence for this is observed in the Kratky plots for the gels, as determined by SAXS (Fig. 2a, Figure S4). Fitting Gaussian curves to the data revealed that a band around $0.13 \AA^{-1}(4.8 \mathrm{~nm})$ present in the pure OCNF sample substantially increased in intensity in the presence of SAs (Table 1, Table S3). Whilst the SA content did not impact the area of the band, the choice of SA resulted in an increase exponentially proportional to the gel complex viscosity fit parameters (Fig. 2b). Given that the band falls within the range $0.03-3 \AA^{-1}$, it is apparent that the presence of the SA affects the macromolecular distances between the fibrils. Thus, it is theorised that the relative hydrophobicity of the SA impacts the fibril spacing, which weakens the gel due to a decrease in the strength of the interfibrillar interactions.

Interaction between the SAs and OCNF was confirmed using DLS and QCM. DLS confirmed that the incorporation of the SA into the suspension resulted in a larger apparent particle size, indicating a change in the hydrodynamic friction of the OCNFs due to the adsorption of the SAs (Table S4). QCM analysis revealed that the SAs were reversibly bound to the OCNFs, as evidenced by the mass loss upon switching back to $\mathrm{H}_{2} \mathrm{O}$ (Fig. 2c). Converting the change in mass to moles and multiplying by the total number of potential hydrogen bond sites per molecule (6, 12 and 20 for glycerol, sorbitol and maltitol respectively) (PubChem 2020a, 2020b, 2020c) resulted in no significant difference between the theoretical number of hydrogen bonds formed for all three SAs (Table S6). This suggested that adsorption of the SAs resulted from hydrogen bonding. However, the change in mass was approximately one fifth of the change observed upon switching to $\mathrm{D}_{2} \mathrm{O}$, which indicated that SAs could not interact with all the sites accessible to water.

Filament physicochemical properties

Extrusion of the gels into an acetone bath and collection on a curved glass surface resulted in the formation of ribbon-like fibre structures (Fig. 3a). Differences in the FTIR spectra (Fig. 3b) and an increase in the filament cross-sectional area as the SA content increased (Fig. 4a) suggested that the SAs were still present in the filaments after drying. However, these were both indirect measurements as there were no distinct bands that could be directly associated with the SAs themselves in the FTIR spectra and an increase in filament diameter could 


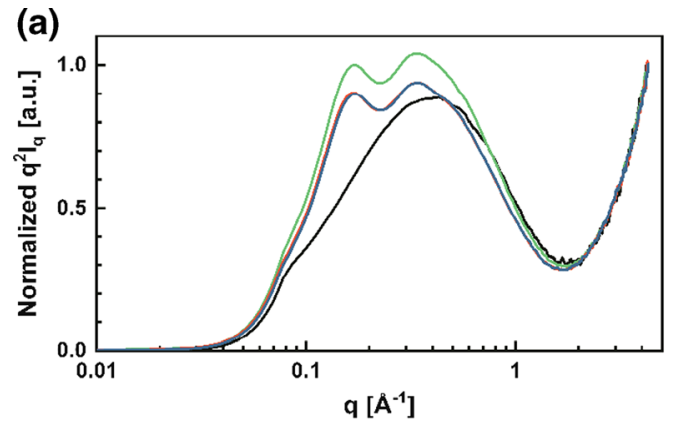

(b)

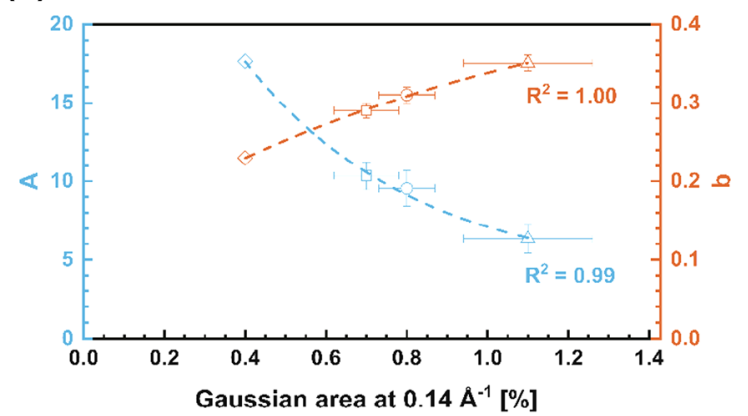

(c)

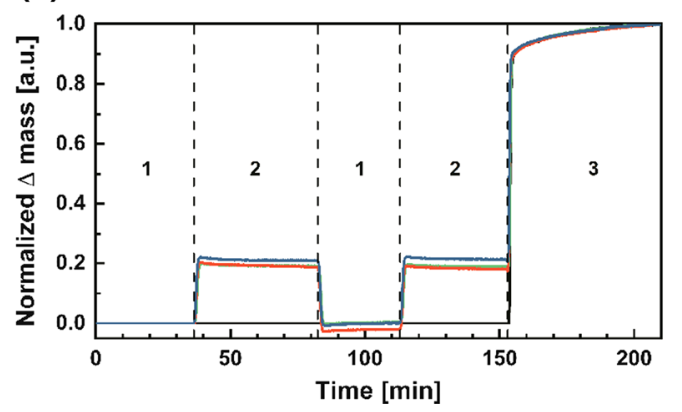

Fig. 2 a Kratky plots for hydrogels with no SA (black line); glycerol (green line); sorbitol (red line); maltitol (blue line) b Comparison between gel structure (area of gaussian fitted to SAXS Kratky plot at $0.14 \AA^{-1}$ ) and rheological properties (complex viscosity parameters $A$ and $b$ ). No SA (diamond), glycerol (triangle), sorbitol (circle), maltitol (square). Exponentials fitted to data (dashed lines) Error: \pm S.E. c QCM analysis of SA interaction with OCNFs. $1: \mathrm{H}_{2} \mathrm{O} ; 2: \mathrm{H}_{2} \mathrm{O}$ (black line), glycerol (green line), sorbitol (red line), maltitol (blue line); $3: \mathrm{D}_{2} \mathrm{O}$

have resulted from an increase in the porosity of the material. It is apparent that the SAs preferentially interacted with the sodium ions present, displacing them from the carboxyl groups, which is observed as a shift in the carboxyl group absorption from ca. $1600 \mathrm{~cm}^{-1}$ to ca. $1720 \mathrm{~cm}^{-1}$ upon protonation (Socrates 2004), observed as a decrease in the 1600:1720 absorption ratio. Maltitol was most effective at this, resulting in the band located at $\sim 1720 \mathrm{~cm}^{-1}$ dominating the band located at $\sim 1600 \mathrm{~cm}^{-1}$, whilst glycerol was least effective (Table 2), reflecting the relative hydrophilicity of the SAs. It has previously been reported that SAs will form complexes with metal ions in the presence of water, which may contribute to this observation, although this is only significant for divalent and trivalent cations rather than monovalent ions, such as sodium (Tiihonen et al. 2002). TGA analysis (Figure S5a) of the filaments confirms the retention of the sugar alcohols after extrusion and drying as evidenced by a decrease in the final mass inversely proportional to the sugar alcohol content (Fig. 3c) and the presence of two mass differential peaks attributed to the nanocellulose (differential centre: $269^{\circ} \mathrm{C}$ ) and the sugar alcohol (maltitol differential centre: $326^{\circ} \mathrm{C}$ ) (Fig. 3d, Figure S5b).

The inclusion of the SAs enabled the continuous production of flexible fibres, unlike the pure OCNF filaments that were highly brittle and susceptible to breaking at the acetone/air interface (limiting their ability to be tested). As expected of a plasticiser, an increase in the SA content resulted in an increase in the strain at break from 1 to $4 \%$ (Fig. 4b), whilst the ultimate tensile strength and Young's modulus decreased (Fig. 4c,d). Whilst the increase in crosssectional area and strain at break were independent of the choice of SA, both the tensile strength and Young's modulus demonstrated dependency. Glycerol resulted in significantly weaker fibres than sorbitol and maltitol. For example, at $30 \mathrm{wt} . \%_{\text {dry }}$ SA, the Young's moduli for glycerol and sorbitol/maltitol are 19\% $(2.2 \mathrm{GPa})$ and $\sim 39 \%(4.4 \mathrm{GPa})$ of the predicted pure OCNF modulus (11.4 GPa) respectively. This reflects results previously observed by Mathew and Dufresne (2002) with starch, and Csiszár and Nagy (2017) with cellulose nanocrystals. In this case, the possibility exists that the protonation of the carboxyl groups (Table 2) promotes hornification-defined as esterification between carboxyl and hydroxyl groups (Fernandes Diniz et al. 2004) —of the material, resulting in improved tensile properties for maltitol and sorbitol modified materials compared to glycerol. It is noted that the predicted Young's modulus and ultimate tensile strength of $11.4 \pm 1.6 \quad \mathrm{GPa}$ and $101.5 \pm 16.5 \mathrm{MPa}$ respectively at $0 \mathrm{wt} . \%_{\text {dry }} \mathrm{SA}$ are similar to those first reported by Iwamoto et al. (2011) at a similar extrusion rate (Iwamoto: $11.6 \pm 2.1 \mathrm{GPa}$, 
(a)
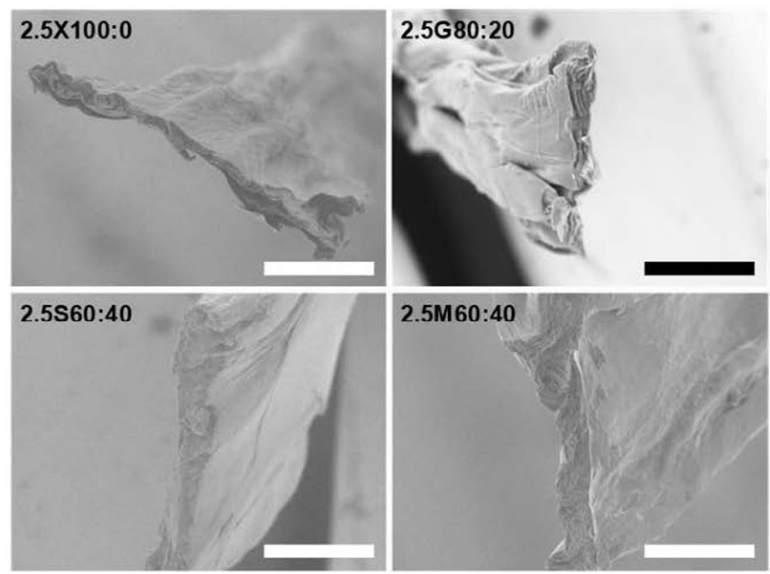

(c)

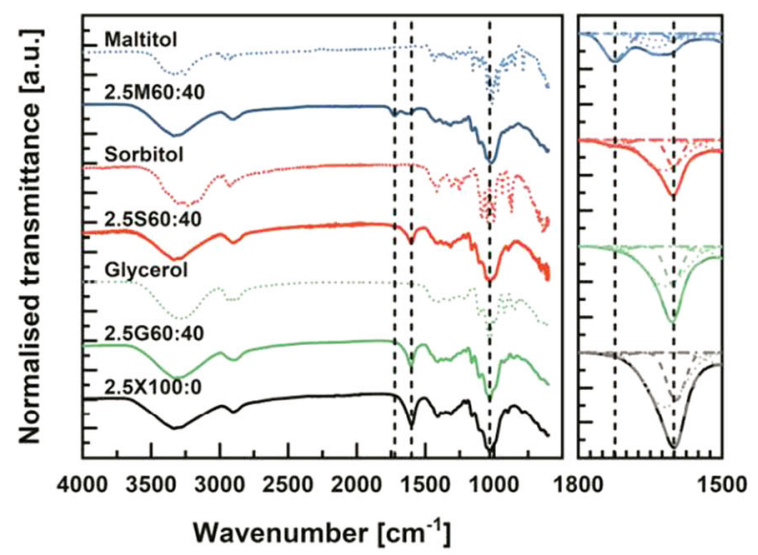

Fig. 3 a SEM images of extruded OCNF filaments with, and without, addition of SAs. Scale bar: $100 \mu \mathrm{m}$. b Full FTIR spectra of, from top to bottom, pure maltitol (light blue dotted line); 2.5M60:40 (dark blue solid line); pure sorbitol (light red dotted line); 2.5S60:40 (dark red solid line); pure glycerol (light green dotted line); 2.5G60:40 (dark green solid line); and 2.5X100:0 (black solid line) plus detail of bands associated with carboxyl groups between 1800 and $1500 \mathrm{~cm}^{-1}$. Vertical dashed lines indicate bands centred at 1030, 1600 and $1720 \mathrm{~cm}^{-1}$. Data

$192 \pm 110 \mathrm{MPa}$ at extrusion rate of $1 \mathrm{~m} \mathrm{~min}^{-1}$; this work extrusion rate: $1.5 \mathrm{~m} \mathrm{~min}^{-1}$ ).

Response to immersion in water

It has previously been reported that extrusion into an acid bath promoted hornification, and stabilisation, of OCNF fibres due to the protonation of the carboxyl group (Wang et al. 2019a). Given that the addition of SAs also resulted in protonation of the carboxyl group (b)

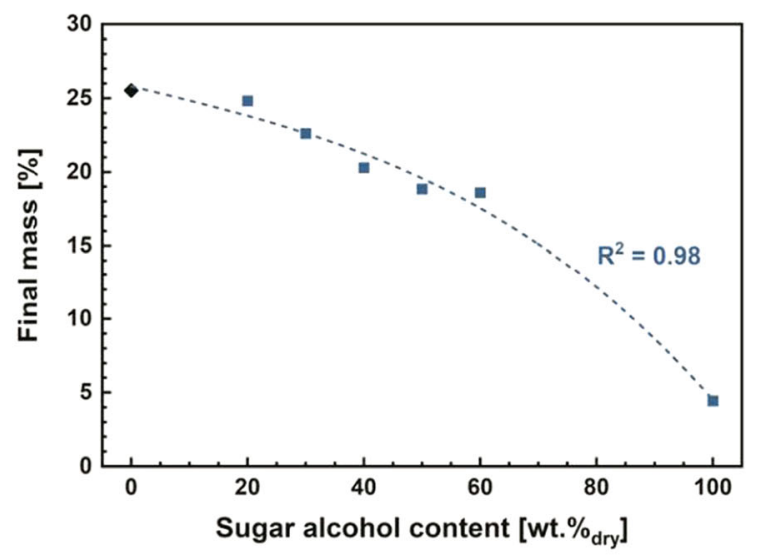

(d)

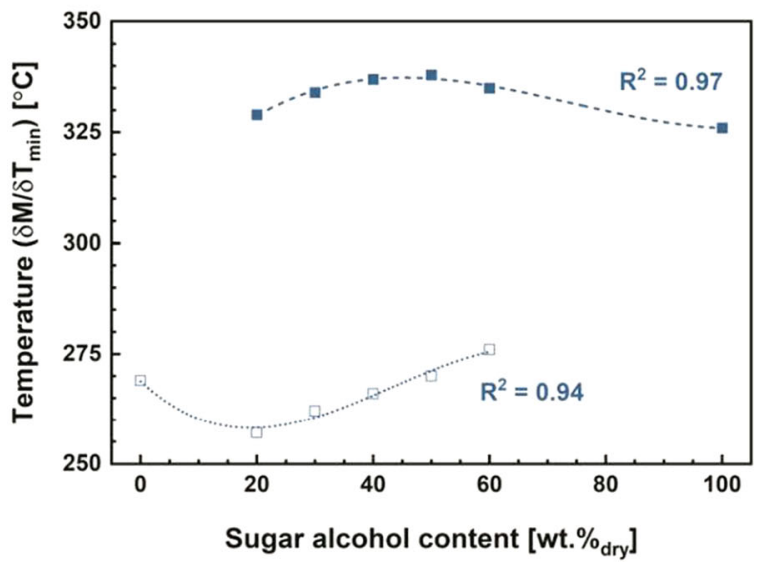

normalized to intensity at $1030 \mathrm{~cm}^{-1}$, corresponding to $\mathrm{C}-\mathrm{O}-\mathrm{C}$ groups in cellulose. All composite spectra were obtained in dry filament form. c Char mass dependent on SA content after heat treatment up to $800{ }^{\circ} \mathrm{C}$. Pure OCNF (black diamond); maltitol (blue squares); cubic polynomial fit (dashed blue line) d Fitted differential peak temperatures related to OCNF (open symbols) and sugar alcohol (closed symbols). Pure OCNF (black diamond); maltitol (blue squares); cubic polynomial fits applied to OCNF peaks (dotted lines) and SA peaks (dashed lines)

(Table 2), the responses of the SA-modified filaments upon immersion in water were tracked over $30 \mathrm{~min}$ by MCLSS. As previously reported in an earlier publication (Johns et al. 2020), the addition of water caused the formation of $\mathrm{COO}^{-}$groups, electrostatically repelling the fibrils from each other, resulting in the rapid expansion of the filament and its ultimate dispersion. This is observed as an increase in the background fluorescence as fibrils are dispersed into the aqueous phase (Fig. 5a 2.5X100:0). However, the 
(a)

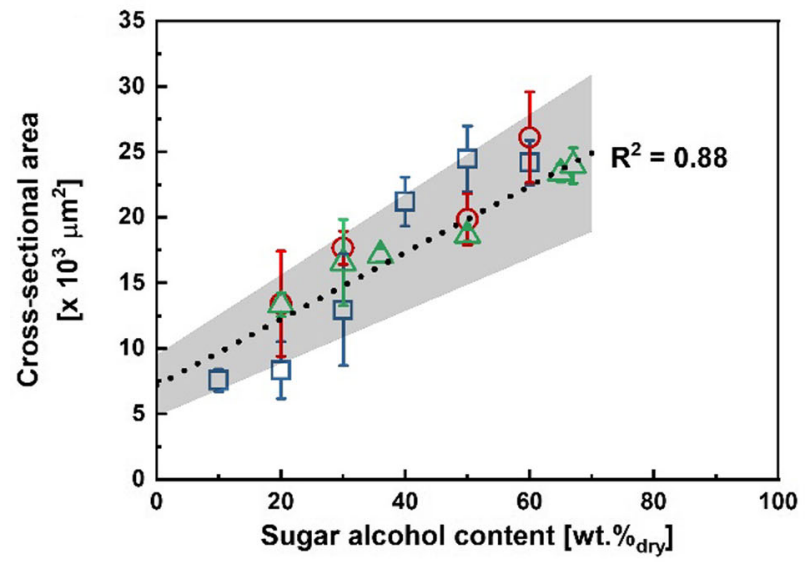

(c)

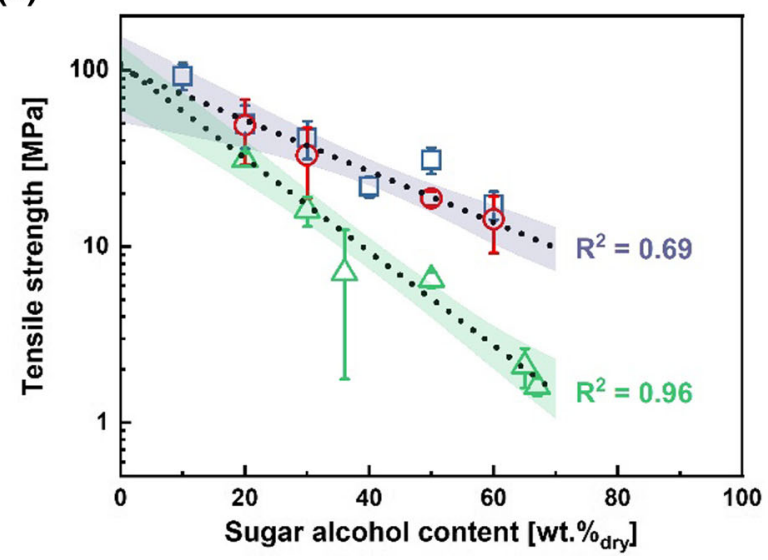

Fig. 4 Physical properties of filaments produced from OCNF with varying sugar alcohol contents. a cross-sectional area, b strain at break, c ultimate tensile strength, and d Young's modulus. Sugar alcohols are glycerol (green triangles), sorbitol (red circles), and maltitol (blue squares). Lines of best fit (black

Table 2 Normalized absorption intensity and ratio of fitted FTIR bands (Figure S6) relating to the fibril carboxyl groups. $1600 \mathrm{~cm}^{-1}$ is attributed to the carboxyl group in the ionic state $\left(\left[\mathrm{COO}^{-}\right]\left[\mathrm{Na}^{+}\right]\right)$; and $1720 \mathrm{~cm}^{-1}$ is attributed to the carboxyl (b)

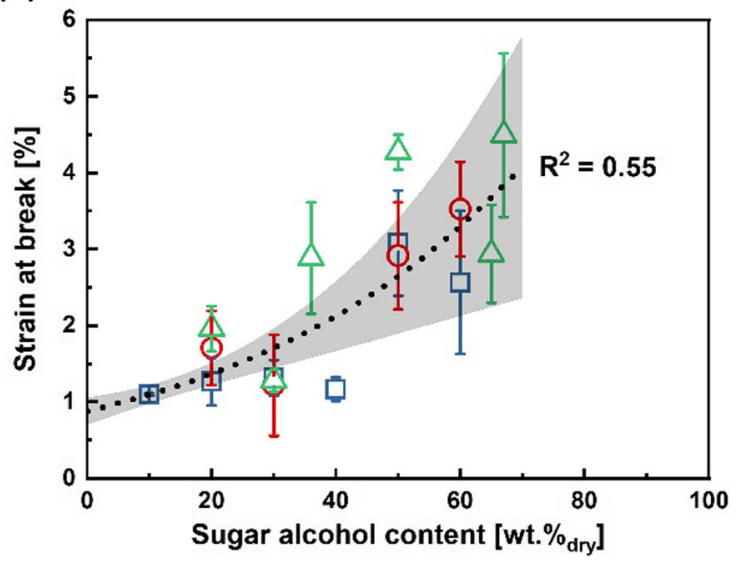

(d)

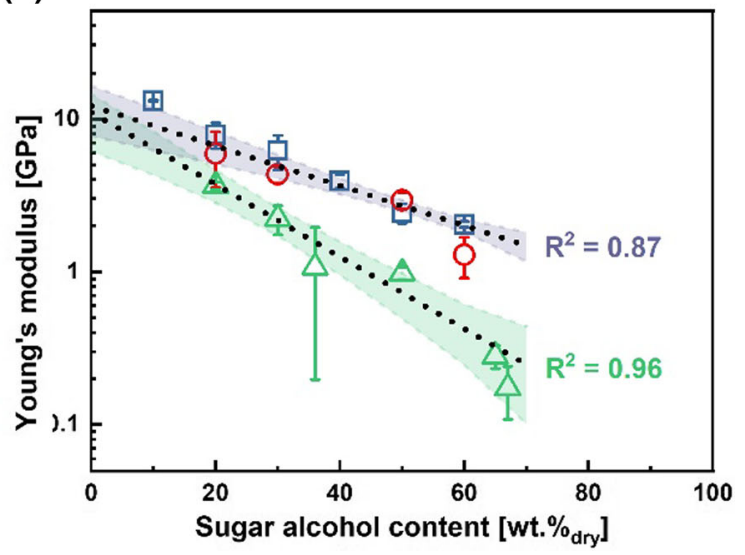

dotted lines) determined with $95 \%$ confidence intervals (black: all three sugar alcohols; purple: sorbitol and maltitol; green: glycerol). Error: \pm S.E. $\mathrm{N}=1, \mathrm{n}=5$. Representative stressstrain curves may be found in the SI (Figure S7)

group in the protonated state $(\mathrm{COOH})$. Bands normalized to intensity of absorption at $1030 \mathrm{~cm}^{-1}$ (attributed to $\mathrm{C}-\mathrm{O}-\mathrm{C}$ groups)

\begin{tabular}{llllll}
\hline Sample & \multicolumn{2}{l}{ Band intensity [a.u.] } & & \multirow{2}{*}{ Ratio 1600:1720 } \\
\cline { 2 - 5 } & $1600 \mathrm{~cm}^{-1}$ & $1620 \mathrm{~cm}^{-1}$ & $1640 \mathrm{~cm}^{-1}$ & $1720 \mathrm{~cm}^{-1}$ & 27.0 \\
\hline $2.5 \mathrm{X} 100: 0$ & 0.27 & 0.31 & - & 0.01 & 10.5 \\
$2.5 \mathrm{G} 60: 40$ & 0.21 & 0.23 & - & 0.02 & 5.0 \\
$2.5 \mathrm{~S} 60: 40$ & 0.15 & 0.17 & 0.03 & 0.15 & 0.2 \\
$2.5 \mathrm{M} 60: 40$ & 0.03 & 0.04 & 0.08 & 0.15 & \\
\hline
\end{tabular}


Fig. 5 Response of SA modified filaments to immersion in water by SA type. a MCLSS images of filaments in the dry state, after deprotonation, and after $30 \mathrm{~min}$. b Initial expansion ratio $(<30 \mathrm{~s}$ max diameter: $0 \mathrm{~s}$ diameter); final expansion ratio (30 min diameter: $0 \mathrm{~min}$ diameter); initial (<30 s) expansion rate $\left(\mu \mathrm{m} \mathrm{min}{ }^{-1}\right)$ divided by initial filament diameter $(\mu \mathrm{m})$; and final (15-30 min) expansion rate $\left(\times 10^{-2} \mu \mathrm{m} \mathrm{min}^{-1}\right)$ divided by initial filament diameter $(\mu \mathrm{m})$. c Comparison of 468:504 emission intensity ratios of the filaments in the dry, deprotonated (deprot), and final states. (2.5X100:0: white; Glycerol: green, upwards hash; Sorbitol: red, downwards hash; Maltitol: blue, double hash)

Error: \pm S.E. $\mathrm{N}=3, \mathrm{n}=1$. $* p<0.05$ compared to unmodified (2.5X100:0) value
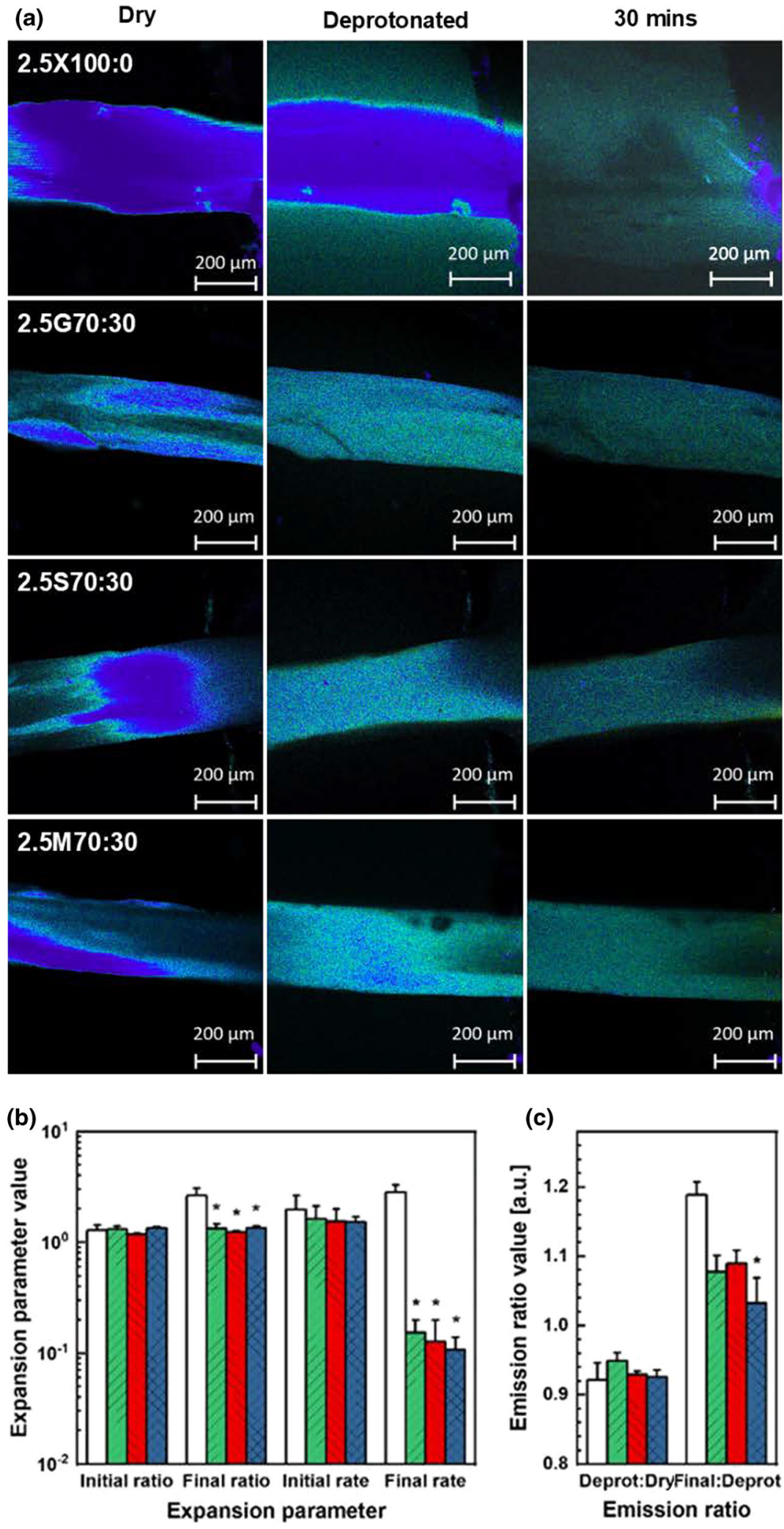
inclusion of SAs in the fibres inhibits this expansion, resulting in the formation of water stable materials where no background fluorescence is observed, even after $30 \mathrm{~min} \quad$ (Fig. 5a 2.5G70:30, 2.5S70:30, 2.5M70:30). As such, the final expansion ratios (final diameter/initial diameter) for the SA-modified fibres, averaging 1.3, are significantly lower than the ratio for the unmodified fibre; a value of 2.6 (Fig. 5b, Figure S8a). Increasing the SA concentration did not significantly affect the final expansion ratio across the range investigated (Figure S9).

All the filaments investigated undergo two distinct expansion phases, the first during the initial $30 \mathrm{~s}$ after immersion and the second over a longer period (Figure S8a). Whilst there is a slight decrease in the initial rate of expansion by SA type relative to the degree of carboxyl group protonation, no significant difference is observed between type, or concentration, which results in no difference observed in the initial expansion ratio (Fig. 5b, Figure S9). This expansion corresponded to a decrease in the 468:504 nm intensity ratio for all the samples (Figure S8b, Table S7), which has previously been associated with ionization of carboxyl groups (Johns et al. 2020). Whilst slight variation in the ratio between the dry and 'deprotonated' states was observed between SA types, as with the initial expansion rate, no significant difference was observed (Fig. 5c). Therefore, it is concluded that the initial expansion phase, which is essentially swelling of the filament, is not significantly impacted by the inclusion of the SAs despite the apparent shift from $\left[\mathrm{COO}^{-}\right]\left[\mathrm{Na}^{+}\right]$to $\mathrm{COOH}$ after drying in their presence.

Unlike the initial swelling, the final expansion rate is significantly lower in the presence of SAs compared to the unmodified filaments (Fig. 5b), which determines the final expansion ratio. It was originally theorised that the presence of SAs could promote hornification between the fibrils, as per acidification. However, based on the FTIR data (Table 2), it would be expected that the glycerol-modified samples would continue to expand in a similar manner to $2.5 \times 100: 0$ as there is a minimal shift to the protonated form of the carboxyl group. That said, from the rheological experiments (Table 1), glycerol was best at screening the repulsive interactions between the fibrils, which originally resulted in weaker gels, whilst the more hydrophilic maltitol was worst. Therefore, it is theo- rized that maltitol promotes hornification of the fibrils due to protonation in the dry phase, which inhibits further expansion of the filaments beyond the initial swelling phase. Conversely, glycerol does not promote hornification. Rather, its presence inhibits the fibrils from repelling one another thus inhibiting further expansion. This is supported by the change in the 468:504 $\mathrm{nm}$ autofluorescent intensity ratio between the ionized and final states (Fig. 5c, Table S4), whereby separation of the fibrils results in an increase in the observed ratio (Johns et al. 2020). The fibrils in the 2.5X100:0 filaments become well-spaced from one another, resulting in a $19 \%$ increase in the ratio, whilst the fibrils in maltitol-modified filaments remain aggregated, resulting in a significantly lower (3\%) increase over the same time period. The glycerol- and sorbitol-modified fibrils are less inhibited than those present in the maltitol sample, resulting in an average increase of $8 \%$ in both cases.

Additional analysis for the response of filament immersion in water was performed using QCM. Exposure of the pure OCNF film to $\mathrm{D}_{2} \mathrm{O}$ resulted in a loss of mass upon switching back to water (Fig. 6a) This mass loss was attributed to the enhanced dispersion of the nanocellulose in the presence of $\mathrm{D}_{2} \mathrm{O}$, in line with the dispersion of the pure OCNF filament as observed by confocal microscopy (Fig. 5a). However, the presence of the SAs changed this response. At low SA contents the mass loss was less than that of the pure OCNF film, whilst higher contents resulted in a greater mass loss (Fig. 6a). However, significant mass loss was also observed whilst the high content films were immersed in $\mathrm{D}_{2} \mathrm{O}$. As OCNF is not observed to disperse in the SA modified filaments, this mass loss is attributed to the dissolution of excess SA present in the films, which would not be detected by the confocal microscopy technique. Taking the dissolution of the SA into account, the calculated change in mass after the switch to $\mathrm{D}_{2} \mathrm{O}$ and back to $\mathrm{H}_{2} \mathrm{O}$ confirms that dispersion of the OCNF is completely inhibited within the time frame studied by using sorbitol, or maltitol, at higher SA contents (Fig. 6b, Table S7). We acknowledge that whilst the presence of SAs inhibits dispersion of OCNF, enhancing the wet stability of the filaments, the mass loss at high SA contents may negatively impact the wet strength of the filaments. 

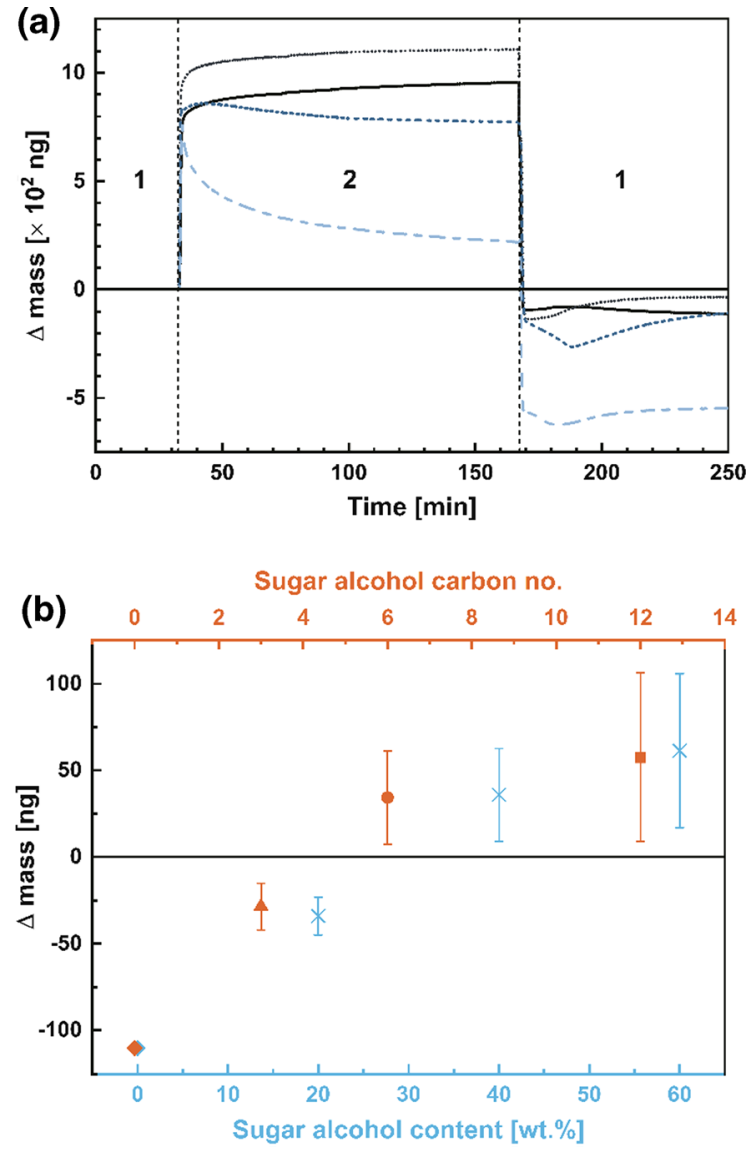

Fig. 6 a QCM data for 2.5X100:0 (black solid line); 2.5M80:20 (dark blue dotted line); 2.5M60:40 (blue short dashed line); 2.5M40:60 (light blue dashed line). $1 . \mathrm{H}_{2} \mathrm{O} ; 2 . \mathrm{D}_{2} \mathrm{O}$. b Average change in mass dependent on sugar alcohol content (light blue crosses) and sugar alcohol chain length (light brown) after exposure to $\mathrm{D}_{2} \mathrm{O}$ and re-immersion in $\mathrm{H}_{2} \mathrm{O}$. No SA (diamond); glycerol (triangle); sorbitol (circle); maltitol (square). $\mathrm{N}=3$, $\mathrm{n}=1$; Error: \pm S.E

\section{Conclusions}

The incorporation of SAs (glycerol, sorbitol and maltitol) into OCNF gels and extruded filaments affect their physicochemical properties, resulting in weaker gels but enabling the continuous production of filaments that are stable upon immersion in water. It is proposed that the relative hydrophilicity of the SA and its ability to protonate the surface carboxyl groups are important parameters in predicting the gel and filament response. Glycerol, the least hydrophilic SA investigated, appears to inhibit repulsive interactions between fibrils, weakening the gels but also inhibiting filament dispersion upon immersion in water.
Conversely, the incorporation of maltitol, the most hydrophilic SA, results in protonation of the surface carboxyl groups upon drying, which is presumed to promote hornification between the hydroxyl groups and carboxyl groups present, although the exact mechanism behind this is unknown. This also inhibits filament dispersion upon immersion in water. Whilst the precise mechanism behind the stabilisation of the OCNF filaments in the presence of SAs is not yet known, nor whether all SAs interact in the same manner, we conclude that their use opens further opportunities for tailoring the properties of OCNFbased gels and filaments without the need for post extrusion processing.

Acknowledgments SJE, MAJ and RN would like to thank the Engineering and Physical Sciences Research Council (EPSRC) for provision of financial support grant no. (EP/N03340X/2). MAJ would also like to thank the Mitacs Accelerate scheme for additional funding (ORS RPB (GR018401)). We gratefully acknowledge Dr Michael Zachariadis and the Material and Chemical Characterisation Facility $\left(\mathrm{MC}^{2}\right)$ at the University of Bath, http://go.bath.ac.uk/mc2, for their support and assistance in this work with regards to MCLSS; Dr Zakir Hussein for assistance with SAXS acquisition, and Ass. Prof. Feng Jiang for access to the QCM.

\section{Declarations}

Conflict of interest The authors declare there are no conflicts of interest.

Open Access This article is licensed under a Creative Commons Attribution 4.0 International License, which permits use, sharing, adaptation, distribution and reproduction in any medium or format, as long as you give appropriate credit to the original author(s) and the source, provide a link to the Creative Commons licence, and indicate if changes were made. The images or other third party material in this article are included in the article's Creative Commons licence, unless indicated otherwise in a credit line to the material. If material is not included in the article's Creative Commons licence and your intended use is not permitted by statutory regulation or exceeds the permitted use, you will need to obtain permission directly from the copyright holder. To view a copy of this licence, visit http://creativecommons.org/licenses/by/4.0/.

\section{References}

Alves L, Ferraz E, Gamelas JAF (2019) Composites of nanofibrillated cellulose with clay minerals: a review. Adv Colloid Interface Sci 272:101994. https://doi.org/10.1016/ j.cis.2019.101994 
Alves L, Ferraz E, Lourenço AF, Ferreira PJ, Rasteiro MG, Gamelas JAF (2020) Tuning rheology and aggregation behaviour of TEMPO-oxidised cellulose nanofibrils aqueous suspensions by addition of different acids. Carbohydr Polym 237:116109. https://doi.org/10.1016/j. carbpol.2020.116109

Benselfelt T, Nordenström M, Lindström SB, Wågberg L (2019) Explaining the exceptional wet integrity of transparent cellulose nanofibril films in the presence of multivalent ions-Suitable substrates for biointerfaces. Adv Mater Interfaces 6:1900333. https://doi.org/10.1002/admi. 201900333

Crawford RJ, Edler KJ, Lindhoud S, Scott JL, Unali G (2012) Formation of shear thinning gels from partially oxidised cellulose nanofibrils. Green Chem 14:300-303. https://doi. org/10.1039/c2gc16302k

Csiszár E, Nagy S (2017) A comparative study on cellulose nanocrystals extracted from bleached cotton and flax and used for casting films with glycerol and sorbitol plasticisers. Carbohydr Polym 174:740-749. https://doi.org/10. 1016/j.carbpol.2017.06.103

da Silva MA, Calabrese V, Schmitt J, Celebi D, Scott JL, Edler KJ (2018) Alcohol induced gelation of TEMPO-oxidized cellulose nanofibril dispersions. Soft Matter 14:9243-9249. https://doi.org/10.1039/C8SM01815D

De France KJ, Hoare T, Cranston ED (2017) Review of hydrogels and aerogels containing nanocellulose. Chem Mater 29:4609-4631. https://doi.org/10.1021/acs. chemmater.7b00531

Fernandes Diniz JMB, Gil MH, Castro JAAM (2004) Hornification-its origin and interpretation in wood pulps. Wood Sci Technol 37:489-494. https://doi.org/10.1007/s00226003-0216-2

Galdeano MC, Grossmann MVE, Mali S, Bello-Perez LA, Garcia MA, Zamudio-Flores PB (2009) Effects of production process and plasticizers on stability of films and sheets of oat starch. Mater Sci Eng C 29:492-498. https:// doi.org/10.1016/j.msec.2008.08.031

Grande R, Trovatti E, Carvalho AJF, Gandini A (2017) Continuous microfiber drawing by interfacial charge complexation between anionic cellulose nanofibers and cationic chitosan. J Mater Chem A 5:13098-13103. https:// doi.org/10.1039/c7ta02467c

Grembecka M (2019) Sugar alcohols. In: Melton L, Shahidi F, Varelis P (eds) Encyclopedia of food chemistry. Academic Press, Oxford, pp 265-275

He Y-D, Zhang Z-L, Xue J et al (2018) Biomimetic optical cellulose nanocrystal films with controllable iridescent color and environmental stimuli-responsive chromism. ACS Appl Mater Interfaces 10:5805-5811. https://doi.org/ 10.1021/acsami.7b18440

Iwamoto S, Isogai A, Iwata T (2011) Structure and mechanical properties of wet-spun fibers made from natural cellulose nanofibers. Biomacromol 12:831-836. https://doi.org/10. 1021/bm101510r

Johns MA, Lewandowska AE, Green E, Eichhorn SJ (2020) Employing photoluminescence to rapidly follow aggregation and dispersion of cellulose nanofibrils. Analyst 145:4836-4843. https://doi.org/10.1039/d0an00868k

Jost V, Kobsik K, Schmid M, Noller K (2014) Influence of plasticiser on the barrier, mechanical and grease resistance properties of alginate cast films. Carbohydr Polym 110:309-319. https://doi.org/10.1016/j.carbpol.2014.03. 096

Lundahl MJ, Cunha AG, Rojo E, Papageorgiou AC, Rautkari L, Arboleda JC, Rojas OJ (2016) Strength and water interactions of cellulose I filaments wet-spun from cellulose nanofibril hydrogels. Sci Rep 6:30695. https://doi.org/10. 1038/srep30695

Lundahl MJ, Klar V, Ajdary R, Norberg N, Ago M, Gisela Cunha A, Rojas OJ (2018) Absorbent filaments from cellulose nanofibril hydrogels through continuous coaxial wet spinning. ACS Appl Mater Interfaces 10:27287-27296. https://doi.org/10.1021/acsami.8b08153

Mathew AP, Dufresne A (2002) Plasticized waxy maize starch: effect of polyols and relative humidity on material properties. Biomacromol 3:1101-1108. https://doi.org/10. 1021/bm020065p

Meng Y, Cao Y, Ji H, Chen J, He Z, Long Z, Dong C (2020) Fabrication of environmental humidity-responsive iridescent films with cellulose nanocrystal/polyols. Carbohydr Polym 240:116281. https://doi.org/10.1016/j.carbpol. 2020.116281

Mittal N, Ansari F, Gowda VK, Brouzet C, Chen P, Larrson PT, Roth SV, Lundell F, Wågberg L, Kotov NA, Söderberg LD (2018) Multiscale control of nanocellulose assembly: transferring remarkable nanoscale fibril mechanics to macroscale fibers. ACS Nano 12:6378-6388. https://doi. org/10.1021/acsnano.8b01084

Mittal N, Benselfelt T, Ansari F, Gordeyeva K, Roth SV, Wågberg L, Söderberg LD (2019) Ion-specific assembly of strong, tough, and stiff biofibers. Angew Chem Int Ed 58:18562-18569. https://doi.org/10.1002/anie.201910603

Moon RJ, Martini A, Nairn J, Simonsen J, Youngblood J (2011) Cellulose nanomaterials review: structure, properties and nanocomposites. Chem Soc Rev 40:3941-3994. https:// doi.org/10.1039/c0cs00108b

Müller CMO, Yamashita F, Laurindo JB (2008) Evaluation of the effects of glycerol and sorbitol concentration and water activity on the water barrier properties of cassava starch films through a solubility approach. Carbohydr Polym 72:82-87. https://doi.org/10.1016/j.carbpol.2007.07.026

PubChem (2020a) PubChem compound summary for CID 753, Glycerol. National Center for Biotechnology Information. https://pubchem.ncbi.nlm.nih.gov/compound/Glycerol. Accessed 21 Aug 2020

PubChem (2020b) PubChem compound summary for CID 5780, Sorbitol. National Center for Biotechnology Information. https://pubchem.ncbi.nlm.nih.gov/compound/Sorbitol. Accessed 21 Aug 2020

PubChem (2020c) PubChem compound summary for CID 493591, Maltitol. National Center for Biotechnology Information. https://pubchem.ncbi.nlm.nih.gov/ compound/Maltitol. Accessed 21 Aug 2020

Saberi B, Chockchaisawasdee S, Golding JB, Scarlett CJ, Stathopoulos CE (2017) Physical and mechanical properties of a new edible film made of pea starch and guar gum as affected by glycols, sugars and polyols. Int J Biol Macromol 104:345-359. https://doi.org/10.1016/j.ijbiomac. 2017.06.051

Schmitt J, Calabrese V, da Silva MA, Lindhoud S, Alfredsson V, Scott JL, Edler KJ (2018) TEMPO-oxidised cellulose 
nanofibrils; probing the mechanisms of gelation via small angle X-ray scattering. Phys Chem Chem Phys 20:16012-16020. https://doi.org/10.1039/c8cp00355f

Socrates G (2004) Infrared and raman characteristic group frequencies: tables and charts, 3rd edn. John Wiley \& Sons Ltd., Chichester

Suyatma NE, Tighzert L, Copinet A, Coma V (2005) Effects of hydrophilic plasticizers on mechanical, thermal, and surface properties of chitosan films. J Agric Food Chem 53:3950-3957. https://doi.org/10.1021/jf048790+

Talja RA, Helén H, Roos YH, Jouppila K (2007) Effect of various polyols and polyol contents on physical and mechanical properties of potato starch-based films. Carbohydr Polym 67:288-295. https://doi.org/10.1016/j. carbpol.2006.05.019

Tiihonen J, Markkanen I, Paatero E (2002) Complex stability of sugars and sugar alcohols with $\mathrm{Na}^{+}, \mathrm{Ca}^{2+}$, and $\mathrm{La}^{3+}$ in chromatographic separations using poly(styrene-CO-divinylbenzene) resins and aqueous organic eluents. Chem Eng Comm 189:995-1008. https://doi.org/10.1080/ 00986440213132

Toivonen MS, Kurki-Suonio S, Wagermaier W et al (2017) Interfacial polyelectrolyte complex spinning of cellulose nanofibrils for advanced bicomponent fibers. Biomacromol 18:1293-1301. https://doi.org/10.1021/acs.biomac. $7 b 00059$

Tong Q, Xiao Q, Lim L-T (2013) Effects of glycerol, sorbitol, xylitol and fructose plasticisers on mechanical and moisture barrier properties of pullulan-alginate-carboxymethylcellulose blend films. Int J Food Sci Technol 48:870-878. https://doi.org/10.1111/ijfs.12039

Torres-Rendon JG, Schacher FH, Ifuku S, Walther A (2014) Mechanical performance of macrofibers of cellulose and chitin nanofibrils aligned by wet-stretching: a critical comparison. Biomacromol 15:2709-2717. https://doi.org/ $10.1021 / \mathrm{bm} 500566 \mathrm{~m}$
Vieira MGA, da Silva MA, dos Santos LO, Beppu MM (2011) Natural-based plasticizers and biopolymer films: a review. Euro Polym J 47:254-263. https://doi.org/10.1016/j. eurpolymj.2010.12.011

Vuoriluoto M, Orelma H, Lundahl M, Borghei M, Rojas OJ (2017) Filaments with affinity binding and wet strength can be achieved by spinning bifunctional cellulose nanofibrils. Biomacromol 18:1803-1813. https://doi.org/10.1021/acs. biomac.7b00256

Walther A, Timonen JVI, Díez I, Laukkanen A, Ikkala O (2011) Multifunctional high-performance biofibers based on wetextrusion of renewable native cellulose nanofibrils. Adv Mater 23:2924-2928. https://doi.org/10.1002/adma. 201100580

Wang L, Lundahl MJ, Greca LG, Papageorgiou AC, Borghei M, Rojas OJ (2019a) Effects of non-solvents and electrolytes on the formation and properties of cellulose I filaments. Sci Rep 9:16691. https://doi.org/10.1038/s41598-019-53215-0

Wang Q, Yao Q, Liu J, Sun J, Zhu Q, Chen H (2019b) Processing nanocellulose to bulk materials: a review. Cellulose 26:7585-7617. https://doi.org/10.1007/s10570-01902642-3

Xu M, Li W, Ma C, Yu H, Wu Y, Wang Y, Chen Z, Li J, Liu S (2018) Multifunctional chiral nematic cellulose nanocrystals/glycerol structural colored nanocomposites for intelligent responsive films, photonic inks and iridescent coatings. J Mater Chem C 6:5391-5400. https://doi.org/10. 1039/c8tc01321g

Zhi W, Hu Y, Yang W, Kai Y, Cao Z (2013) Measurement and correlation of solubility of D-sorbitol in different solvents. J Mol Liq 187:201-205. https://doi.org/10.1016/j.molliq. 2013.07.014

Publisher's Note Springer Nature remains neutral with regard to jurisdictional claims in published maps and institutional affiliations. 